ARTICLE

DOI: $10.1038 / \mathrm{s} 41467-018-03048-8$

OPEN

\title{
Deficiency of a triterpene pathway results in humidity-sensitive genic male sterility in rice
}

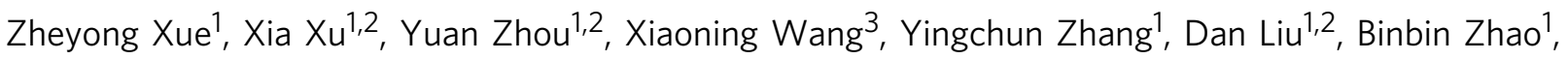 \\ Lixin Duan ${ }^{1,4} \&$ Xiaoquan Qi (i) ${ }^{1}$
}

In flowering plants, the pollen coat protects the released male germ cells from desiccation and damage during pollination. However, we know little about the mechanism by which the chemical composition of the pollen coat prevents dehydration of pollen grains. Here we report that deficiency of a grass conserved triterpene synthase, OsOSC12/OsPTS1, in rice leads to failure of pollen coat formation. The mutant plants are male sterile at low relative humidity $(\mathrm{RH}<60 \%)$, but fully male fertile at high relative humidity $(>80 \%)$. The lack of three major fatty acids in the pollen coat results in rapid dehydration of pollen grains. We show that applying mixtures of linolenic acid and palmitic acid or stearic acid are able to prevent over-dehydration of mutant pollen grains. We propose that humidity-sensitive genic male sterility (HGMS) could be a desirable trait for hybrid breeding in rice, wheat, maize, and other crops.

\footnotetext{
${ }^{1}$ Key Laboratory of Plant Molecular Physiology, Institute of Botany, Chinese Academy of Sciences, Nanxincun 20, Fragrant Hill, Beijing 100093, China.

${ }^{2}$ University of Chinese Academy of Sciences, Yuquan Road 19, Beijing 100049, China. ${ }^{3}$ Department of Natural Product Chemistry, Key Laboratory of Chemical Biology (Ministry of Education), School of Pharmaceutical Sciences, Shandong University, 44 West Wenhua Road, Jinan 250012, China. ${ }^{4}$ Present address: International Institute for Translational Chinese Medicine, Guangzhou University of Chinese Medicine, Guangzhou, 510006 Guangdong, China. Zheyong Xue, Xia Xu and Yuan Zhou contributed equally to this work. Correspondence and requests for materials should be addressed to X.Q. (email: xqi@ibcas.ac.cn)
} 
C onditional male sterility systems facilitate breeding of hybrid varieties with yield advantages in many crops ${ }^{1}$. Photoperiod-/thermo-sensitive genic male sterility (P/ TGMS $)^{2,3}$ that is regulated through a non-coding RNA or small $\mathrm{RNA}^{4-6}$ has been used to generate hybrid varieties of rice (Oryza sativa L.) using a two-line hybrid system, which account $>20 \%$ of the total planting area of hybrid rice in China ${ }^{7}$. However, the sterility may sometimes be compromised by unpredictable fluctuations in temperature ${ }^{8}$. To more fully exploit the potential of two-line hybrid breeding systems, additional conditional male sterility systems could be beneficial.

The pollen coat, the outermost layer of the pollen grain, protects the released pollen grain from desiccation, damage, and pathogen attack, enabling the completion of pollination ${ }^{9,10}$. Chemical analysis of the pollen coat revealed the presence of carotenoids, flavonoids, fatty acids, isoprenoids, glycoconjugates, and many other compounds ${ }^{11-13}$. Rice and other grass species appear to have less thinner pollen coats materials than have been described in Brassicaceae species ${ }^{14-17}$. Mutants that are deficient in pollen coat formation may have conditional male sterile phenotypes ${ }^{18}$.

The constituents of pollen coats include isoprenoids. Oxidosqualene cyclases (OSCs) represent a branch point enzymes in isoprenopid biosynthesis, converting a basic terpenoid precursor, 2,3-oxidosqualene, to a diverse set of functional steroids and triterpenoids, which are often involved in plant defence ${ }^{19-22}$. OsOSC12 is a grass-species-specific triterpene synthase that is expressed in the anther ${ }^{22}$.

In this study, we show that OsOSC12 is a bicyclic triterpene synthase and catalyzes a commited step in a triterpene pathway.

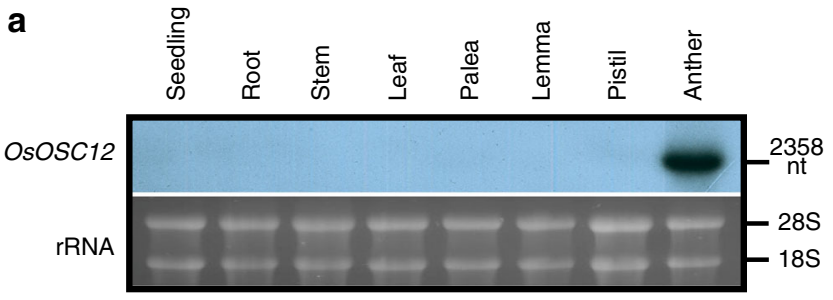

C

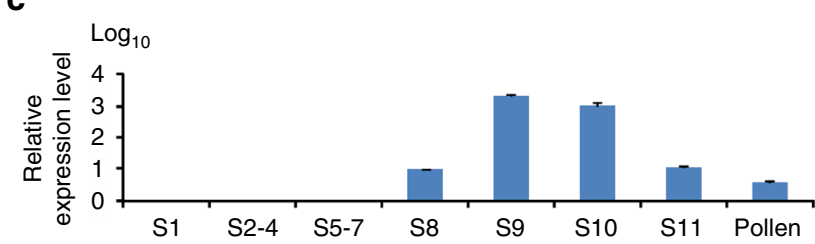

$\mathbf{e}$
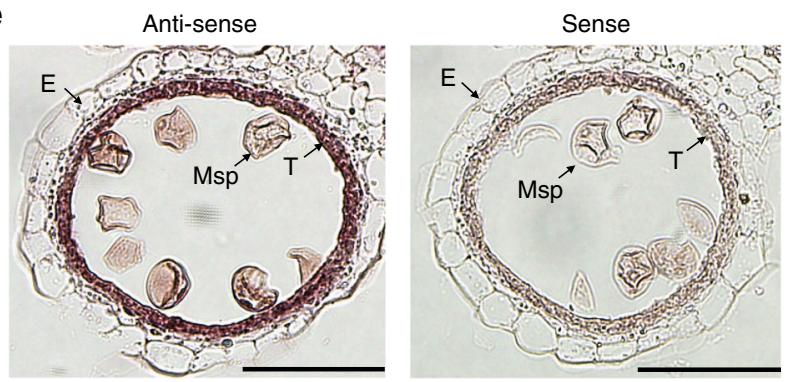

OsOSC12-deffective mutants have less pollen coat material than wild type (WT) and display a humidity-sensitive genic male sterility (HGMS) phenotype.

\section{Results}

Tapetum-specific expression of OsOSC12. Among the annotated 12 rice $\mathrm{OSCs}^{21}$, OsOSC12 is specifically expressed in the anther ${ }^{22}$. OsOSC12 and its encoded protein are expressed in tapetal cells at relatively late stages of anther development ${ }^{14,15}$ from S8 to S11 (Fig. 1 and Supplementary Figs. 1-3). During S10 and 11, as the tapetal cells start to degrade, the lipid bodies are released into the anther lumen and relocate to form an extracellular lipidic coating around maturing pollen grains ${ }^{11,14,15}$. We therefore hypothesized that OsOSC12 is involved in pollen development, specifically in pollen wall formation.

OsOSC12-defective mutants are HGMS. We identified six mutants which carry nonsense or missense mutations for OsOSC12 by screening ethyl methane sulfonate (EMS) or sodium azide-induced rice mutant populations by Targeting Induced Local Lesions IN Genomes (TILLING) method (Fig. 2a and Supplementary Table 1). The E157 mutation induced a premature stop codon and was associated with both a substantial reduction of OsOSC12 transcript abundance and OsOSC12 protein in the anther (Fig. 2b, c and Supplementary Fig. 4). Under normal field conditions (30-39 ${ }^{\circ} \mathrm{C}$, relative humidity; $\left.\mathrm{RH} 40-70 \%\right)$, the level of self fertility shown in E157, S1708, and $\$ 4928$ plants was reduced to $<6 \%$ of WT plants, while E2304, S558, and S1535 plants were all fully self-fertile (Fig. 2d). Genetic analysis (Supplementary b
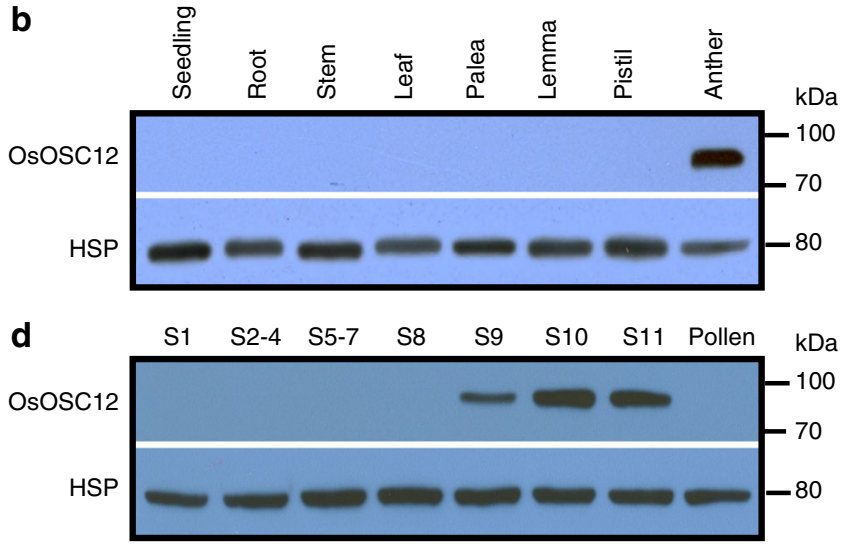

$\mathbf{f}$

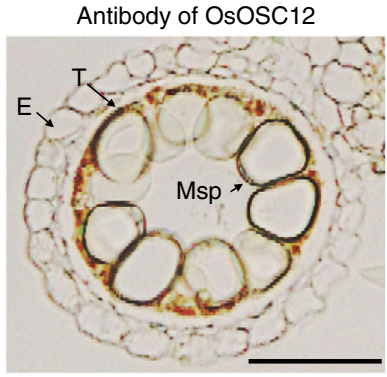

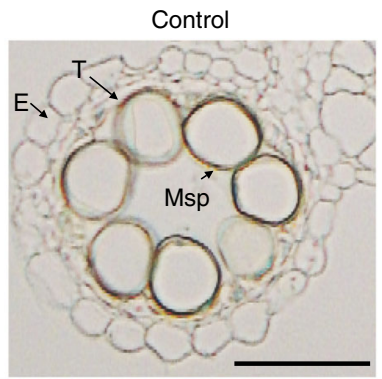

Fig. 1 Transcription and expression of OsOSC12. a, b Tissue specificity as revealed by northern and western blotting. c, d Temporal profiles during anther development, as shown by real-time PCR and western blotting. S1 to S11 correspond to the stages of anther development as described ${ }^{15}$. The values are presented as means \pm s.e., $n=3$. e The localization of OsOSC12 mRNA at S9. Hybridization with sense OsOSC12 transcript provided the negative control. $\mathbf{f}$ Immuno-localization of OsOSC12 at S10. Hybridization with blocking buffer was used as the negative control. The negative controls for northern and western blotting experiments were, respectively, $18 \mathrm{~S}$ and $28 \mathrm{~S}$ rRNA, and the rice heat shot protein Q69QQ6. E epidermis, Msp microspore, T tapetum. Scale bar, $50 \mu \mathrm{m}$ 

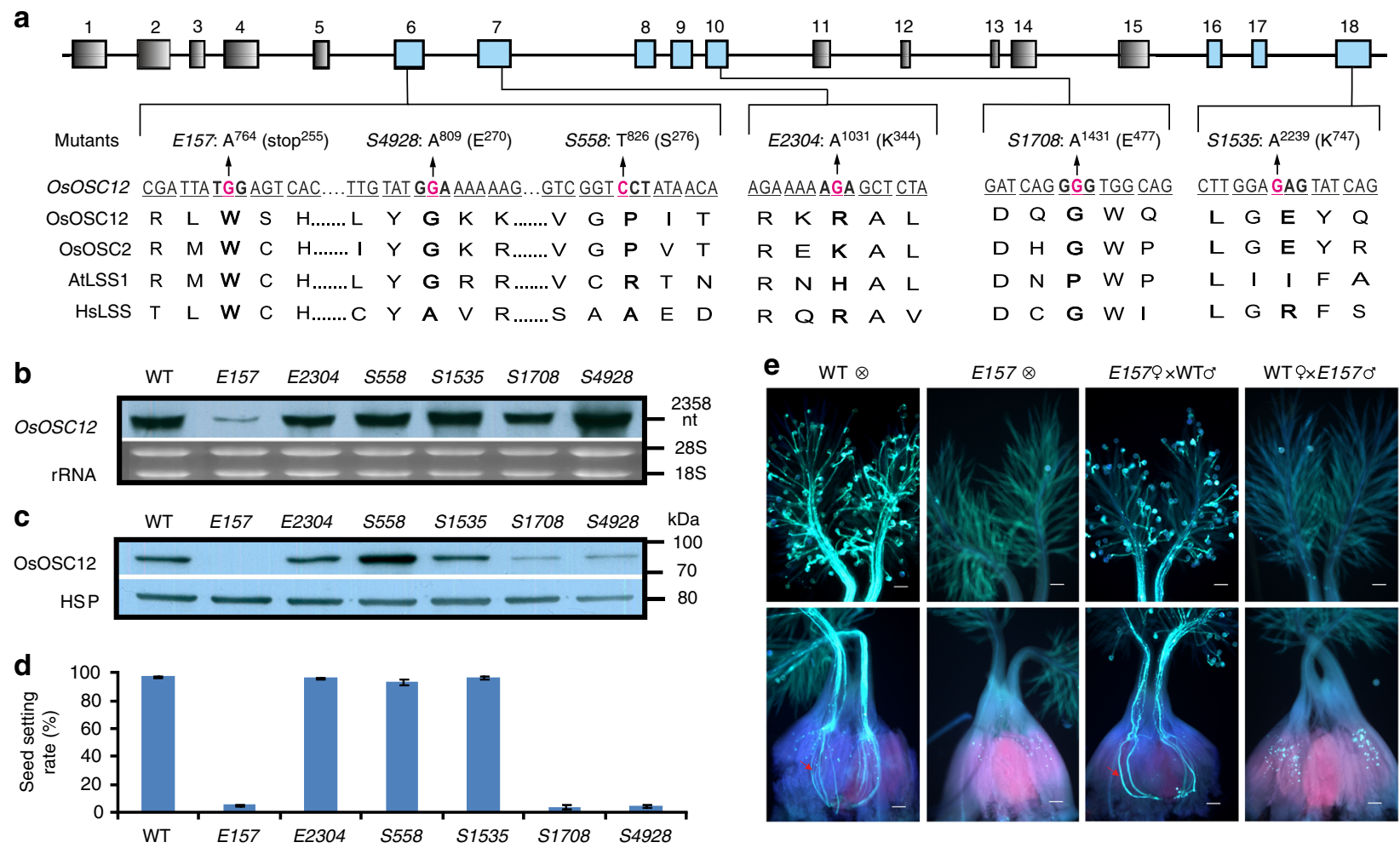

Fig. 2 The absence of OsOSC12 results in male sterility. a OsOSC12 mutants induced by either EMS or sodium azide. Boxes and lines indicate the OsOSC12 exons and introns, respectively. TILLING was directed at exons 6-10 and 16-18 (blue box). Mutated nucleotides are marked in red, and the changed nucleotides and the corresponding amino acids are shown for each mutant. b Northern blot analysis of OsOSC12 transcription. c Western blot analysis of OsOSC12 expression. Negative controls as given in Fig. 1. d Self fertility of field-grown WT and mutant plants (30-39 ${ }^{\circ} \mathrm{C}, 40-70 \%$ RH), based on panicles. The data are presented as mean \pm s.d. $n=15$. e Germination (upper panel) and pollen tube elongation (lower panel) of WT and E157 pollen, imaged $1 \mathrm{~h}$ after pollination. Scale bar, $100 \mu \mathrm{m}$

Table 2) indicated that sterility of mutants E157, S1708, and S4928 was due to recessive mutations of OsOSC12. The allelism test (Supplementary Fig. 5) showed that the E157, S1708, and S4928 mutations all represented loss-of-function OsOSC12 alleles. WT pollen germinated freely on both WT and E157 stigmas, but E157 pollen grains rarely adhered to the stigma and germinated poorly at normal RH (30-60\%) (Fig. 2e). All loss-of-function mutants E157, S1708, and $S 4928$ plants became male fertile when complemented by transformation with the WT OsOSC12 allele (Supplementary Fig. 6). Thus we conclude that mutations of OsOSC12 cause male sterility.

When pollen grains were placed on a detached mature pistil under an RH of $30-60 \%$, WT pollen adhered to the stigma after $20.6 \pm 6.2 \mathrm{~s}(n=178)$ and thereafter developed normally (Fig. 3a), but E157 pollen began to shrink after $18.5 \pm 10.6 \mathrm{~s}(n=103)$, becoming dehydrated by $48.3 \pm 10.4 \mathrm{~s}(n=103)$ (Fig. 3a). As a result, the pollen did not adhere to the stigma and pollen tube elongation was arrested at a very early stage (Supplementary Fig. 7). Exposing the dehydrated E157 pollen to an $\mathrm{RH}$ above $80 \%$ restored both their original shape and their ability to adhere (Fig. 3a and Supplementary Movie 1) and germinate (Supplementary Fig. 7). There was no difference between the ability of E157 and WT pollen to germinate under the conditions of high $\mathrm{RH}$. Thus, OsOSC12 pertains to pollen dehydration, but is not required for pollen recognition, adhesion, or germination.

When freshly shed pollen grains were placed on a glass slide and maintained at $27-32^{\circ} \mathrm{C}$ and $30-60 \% \mathrm{RH}$, E157, S1708, and S4928 grains shrank immediately, becoming fully dehydrated within a minute, while the WT pollen grains adhered to one another, produced exudate and shrank over a period of about 30 $\min$ (Fig. 3b). Seed setting rates of the three mutants were $<2 \%$ when exposed to an $\mathrm{RH}$ of $30-60 \%$, but was $>80 \%$ when the $\mathrm{RH}$ was raised to above $80 \%$ (Fig. $3 \mathrm{c}$, d). This conditional HGMS is due to dehydration and rapid loss of pollen viability at ambient or low relative humidity $(\mathrm{RH}<60 \%)$. This is different from the Arabidopsis pop1 mutant, which loses the ability to absorb water from the stigma ${ }^{18}$.

Three fatty acids prevent pollen dehydration. Transmission electron microscopy (TEM) observation of ultramicrotome and cryo-ultramicrotome pollen sections showed that in contrast to WT, E157 pollen lacked pollen coat material deposited between the tectum and the nexine after anther stage S12 (Fig. 4a-c and Supplementary Figs. 8, 9). It is possible that the lack of this pollen coat materials may cause rapid dehydration of the mutant pollen. To further decipher the chemical constitution of the pollen coat, we developed a method to extract pollen coat compounds (Supplementary Fig. 10), and obtained about 4\% (w/w) pollen coat extract (PCE, $0.2 \mathrm{~g}$ ) from $5 \mathrm{~g}$ pollen grains. Gas chromatography-mass spectrometry (GC-MS) analysis of PCE revealed that long-chain fatty acids, sterols, and several unknown peaks in the region of triterpene esters, were substantially reduced in E157 compared to the WT, while three major phytosterols increased in the mutant E157 (Supplementary Fig. 10). Palmitic acid (16:0) and linolenic acid (18:3), which comprise $3.4 \pm 0.23 \%$ (mean \pm s.d., $n=5$ ) and $6.9 \pm 0.11 \%$ (mean \pm s.d., $n=5$ ) of the WT PCE (w/w), respectively, were decreased 4.93 and 4.51 -fold $(P<0.01$ by Student's $t$ test) in E157 PCE (Fig. 4d). Stearic acid (18:0), which comprised about $2.8 \pm 0.11 \%$ (mean \pm s.d., $n=5$ ) of 
a

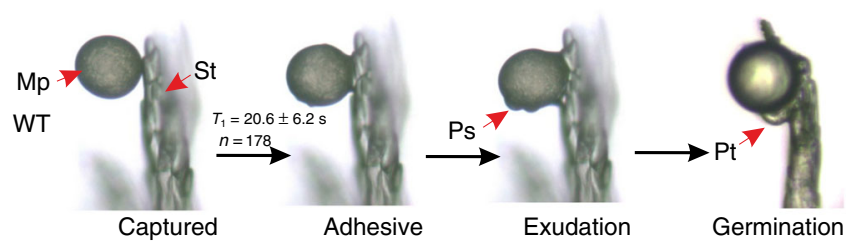

b

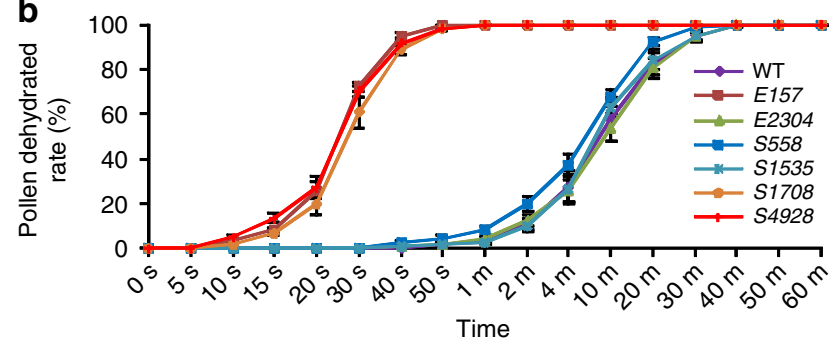

C

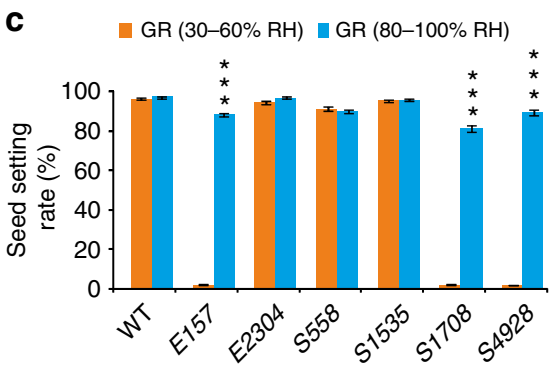

d

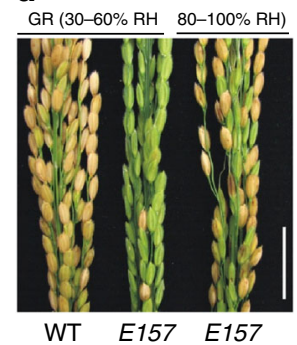

Fig. 3 Characterization of humidity-sensitive genic male sterility. a Germination of WT and mutant pollen on the stigma. $T_{2}$ and $T_{3}$ refer to the period between, respectively, the time when the pollen came into contact with the stigma and the onset of pollen dehydration, and from the onset of dehydration and complete dehydration. Mp mature pollen, Ps protrusion, Pt pollen tube, St stigma. b Pollen dehydration at $27-32^{\circ} \mathrm{C}, 30-60 \% \mathrm{RH}$. The ratio between the numbers of dehydrated and total pollen grains is presented in the form of mean \pm s.d., $n=3$. c Seed set of the WT and mutant plants in different humidity. The data are presented as means \pm s.d., $n=15$. ${ }^{\star \star \star} P<0.001$, Student's $t$ tests. GR growth room. $\mathbf{d}$ Spikelets of the WT and mutant E157 plant grown in different humidity. Scale bar, $2 \mathrm{~cm}$

a

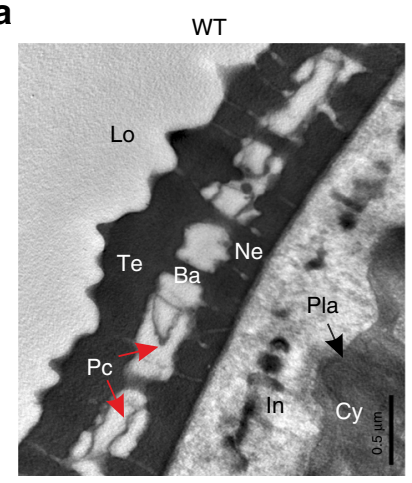

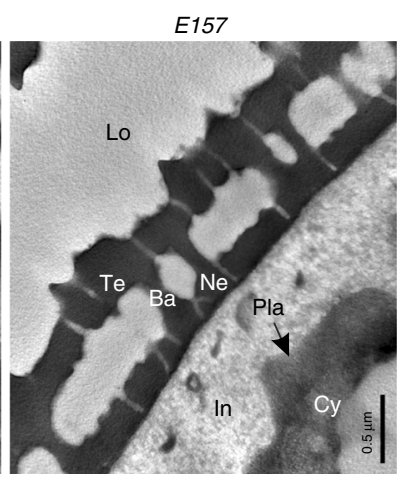

b

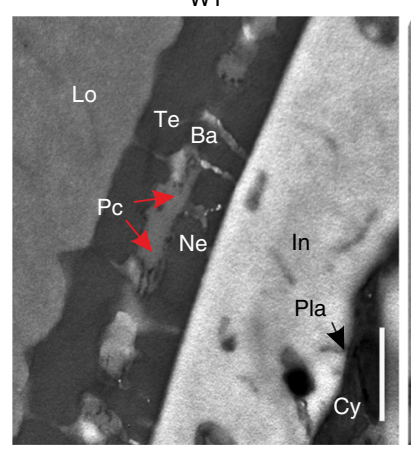

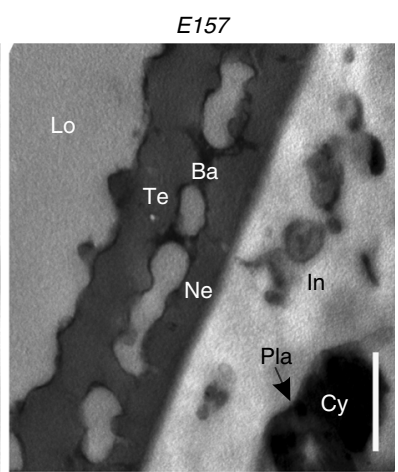

C

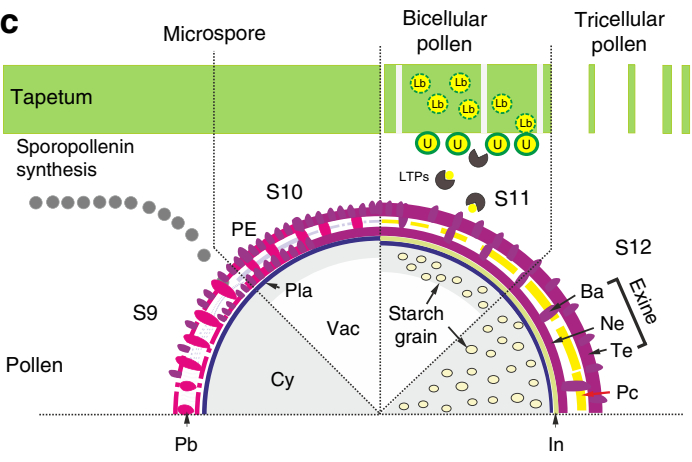

d

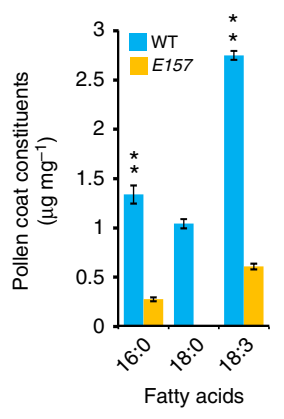

e

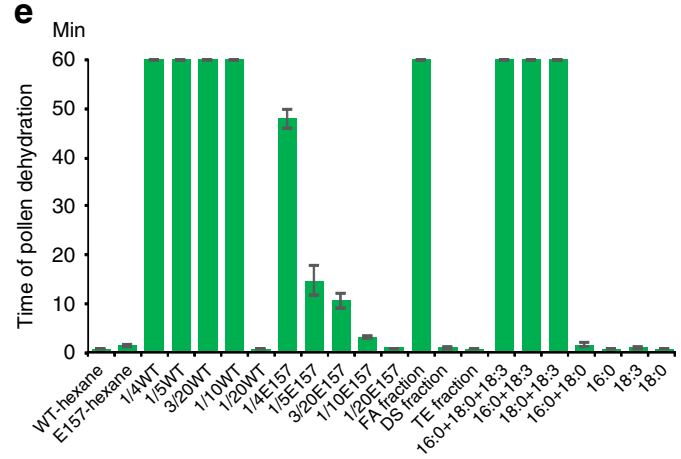

Fig. 4 Identification of pollen coat chemicals. TEM analysis of ultramicrotome (a) and cryo-ultramicrotome (b) sections of the WT and E157 pollen wall at S14. c Proposed mode of pollen coat formation during stages S9 to S12. Ba bacula, Cy cytoplasm, In intine, LTPs lipid transfer proteins, Lo locule, Ne nexine, Pc pollen coat (indicated by red arrows), PE primexine, Pla plasma membrane, Te tectum, $U$ ubisch body, Vac vacuole. $\mathbf{d}$ Analysis of pollen coat lipids of the WT and $E 157$ plants. The values indicate means \pm s.d., $n=5,{ }^{\star \star} P<0.01$, by Student's $t$ test. e Pollen dehydration rates when treated with pollen coat extracts and chemicals. E157-hexane: E157 pollen treated by hexane, WT-hexane: wild-type pollen treated by hexane, abbreviates of fraction and chemical names are listed in Supplementary Table 4. Times of pollen $(n=100-150)$ dehydration are presented in the form of mean \pm s.d., $n=3$. Scale bar, $0.5 \mu \mathrm{m}$ 
the WT PCE (w/w), was not detected in the mutant E157 pollen coat (Fig. 4d).

Notably, exogenous application of WT PCE prolonged the time to dehydration of the mutant $E 157$ pollen from 1 to 2 min to more than $1 \mathrm{~h}$ when at least $1 / 10$ dilution of WT PCE $\left(20 \mathrm{mg} \mathrm{mL}^{-1}\right)$ was added. In contrast, E157 PCE had no obvious effect (Fig. 4e). Fractionation of the WT PCE demonstrated the three major components separated by silica gel chromatography, fatty acids (FA fraction), dehydrated sterols (DS fraction), and triterpene esters fraction (TE fraction), with the ratios of 38:29:33 (w/w/w) (Supplementary Fig. 10). When exogenously applied, it was the FA fraction that was able to prolong mutant pollen hydration ${ }^{23}$. The FA fraction mainly contains three fatty acids (16:0, 18:0, and 18:3) with ratio of 23:19:49 (w/w/w). Application of single fatty acids was unable to effectively maintain mutant pollen hydration, whereas mixtures of 16:0, 18:0, and 18:3 maintain mutant pollen hydration (concentrations above $20 \mathrm{mg} \mathrm{mL}^{-1}$ ). Further investigation demonstrated that mixtures of only two fatty acids such as $16: 0$ and $18: 3$ in a ratio of $23: 49(\mathrm{w} / \mathrm{w})$, or $18: 0$ and $18: 3$ with ratio of 19:49 (w/w), are sufficient for prolonging mutant pollen hydration, but the mixture of 16:0 and 18:0 did not produce this effect (Fig. 4e).

OsOSC12 is a bicyclic triterpene poaceatapetol synthase. Our GC-MS analysis reveal a minor peak at a retention time of 20.3 min in the anther extract profiles of WT and three 'silent' mutants, that are absent in the three loss-of-function mutants (Fig. 5a). High-resolution electrospray ionization (ESI) mass spectrometry analysis detected a molecular ion peak at an $\mathrm{m} / \mathrm{z}$ of $427.3929\left(\mathrm{M}+\mathrm{H}^{+}\right)$, predicting a molecule of constitution $\mathrm{C}_{30} \mathrm{H}_{50} \mathrm{O}$ (Supplementary Fig. 11). Structural data obtained from nuclear magnetic resonance (NMR) analysis (Supplementary Fig. 11, Supplementary Data 1 ) of $\sim 1 \mathrm{mg}$ of this compound isolated from $6 \mathrm{~kg}$ of rice panicles and mass spectrum (Supplementary Fig. 12) identified this as the bicyclic triterpene poaceatapetol (systematic name polypoda-7,13E,17E,21-tetraene$3 \beta$-ol). Pichia pastoris yeast cells expressing WT OsOSC12 and proteins from the three non loss-of-function mutants E2304, S558, and S1535 synthesized poaceatapetol (Supplementary Fig. 12), while those yeasts expressing proteins of loss-of-function mutants, E157, S1708, and S4928 could not produce any of triterpenes. This confirms that OsOSC12 catalyzes the cyclization of 2,3-oxidosqualene into poaceatapetol and is therefore a poaceatapetol synthase (OsPTS1).

Comparative analysis of the non-saponified samples from the WT vs. mutants both of anther (S12) and pollen coat, uncovered three fatty acid (C16:0, oleic acid (C18:1), and C18:0) esters of poaceatapetol in the WT pollen coat (Fig. 5b, $\mathrm{c}$ and Supplementary Figs. 13, 14). Further analysis (Supplementary Figs. 13, 14) indicates $0.31 \pm 0.01 \mathrm{\mu g} \mathrm{m}^{-1}$ (mean \pm s.d., $n=5$ ) triterpene esters rather than free triterpenes are deposited in the pollen coat. However, exogenous application of the TE fraction that includes triterpenes esters could not maintain pollen hydration (Fig. 4e), indicating that poaceatapetol or its derivatives affect pollen dehydration by reducing the accumulation of fatty acids in the pollen coat (Fig. 4c). TEM observation also shows that lipid bodies in the WT tapetum are gradually degraded after S11, but are still maintained at high density and integrity in the E157 tapetum after this stage (Supplementary Fig. 9). These results suggest that deficiency in poaceatapetol synthesis would hinder the transport of fatty acids and other metabolites from tapetum to pollen coat.

HGMS-based hybrid production. As the HGMS lines are male fertile when $\mathrm{RH}$ around the time of anthesis stays reliably above
$80 \%$ but sterile at low RH, we tested whether they could be used for hybrid grain production in places the $\mathrm{RH}$ regime is low $(<60 \%)$. Under field conditions in Beijing in 2012, the seed setting rate on E157 and S4928 panicles in the presence of WT pollen was $\sim 30 \%$ (Fig. 6a, b). This level of fertility is comparable to what can be achieved using cytoplasmic male sterility (CMS)or P/TGMS-based methods ${ }^{24,25}$. The proportion of true $\mathrm{F}_{1}$ hybrid seed, as confirmed by sequencing analysis, was $>93 \%(n=300)$ (Fig. 6a, b). OsOSC12/OsPTS1 appears to be specific to grass species, and homologs are present in important cereal crops (Fig. 6c). Relevant transcripts, poaceatapetol synthase, and poaceatapetol, were all detected in the anthers of barley, maize, and wheat (Fig. 6d-f, Supplementary Fig. 15).

\section{Discussion}

Plant OSC enzymes are known for the diverse cyclization mechanisms they employ in driving an enormous variety of triterpenoids ${ }^{20}$. Here, OsOSC12 committing a new triterpene pathway producing poaceatapetol and its esters. The three fatty acids, palmitic acid, linolenic acid, and stearic acid, in the pollen coat prevent pollen over dehydration. But it is not clear how does this triterpene pathway control the accumulation of fatty acids in the pollen coat. Poaceatapetol or it derivatives could interact with the membrane of lipid body, controlling the degradation process. We indeed observed that degradation of lipid body is delayed in the mutant tapetal cell comparing to that of the WT. Alternatively, they could act as signal molecules in the regulation of lipids transportation. The function of poaceatapetol and it derivatives in accumulation of fatty acids in the pollen coat will be elucidated through cloning more HGMS mutant genes and analyzing their functions.

Current rice farming practices make heavy use of hybrid varieties. Hybrid varieties using two-line hybrid systems relies on conditional male sterility. Although 427 P/TGMS-based two-line rice hybrid combinations had been registered in China by 2010, two-line hybrid rice accounted for only $20 \%$ of the total area of hybrid rice cultivation 8 . TGMS is very sensitive to temperature, so that any fluctuation outside the range $22-24^{\circ} \mathrm{C}$ has a major impact on sterility ${ }^{3}$ while PGMS is also influenced by photoperiod requiring day length above 13.5-14 $\mathrm{h}$ during development of younger panicles ${ }^{2}$. These strict requirements limit two-line hybrid rice production and cultivation. In contrast, HGMS is not influenced by temperature and photoperiod and so could potentially be used in hybrid rice breeding in areas where the $\mathrm{RH}$ is below $60 \%$.

Although unexpected fluctuations in humidity, especially caused by rain during flowering, might impede HGMS-based hybrid seed production there are many suitable dry regions, such as in Urumqi, Xinjiang, China, where RH above $80 \%$ was only observed three times between 2005 and 2014 (Supplementary Fig. 16). More extensive field trials in additional locations would be required for further development. Given that the causal gene for the HGMS trait is now known to be OsPTS1, back-crossing the trait into any genetic background should be feasible. Likewise, the conservation of PTS1 in grass species suggests HGMS may be applicable to other important crops such as wheat, barley and maize via identification of induced PTS1 loss-of-function mutants or use targeted knockout strategies.

\section{Methods}

Plant materials and growing conditions. Rice plants were grown either in a growth room delivering a $12 \mathrm{~h}$ photoperiod under normal $\left(30-60 \% \mathrm{RH}, 25-35^{\circ} \mathrm{C}\right)$ or high humidity $\left(>80 \% \mathrm{RH}, 25-35^{\circ} \mathrm{C}\right)$ conditions, or in the field at the Institute of Botany, Chinese Academy of Sciences, Beijing $\left(40-70 \% \mathrm{RH}, 30-39^{\circ} \mathrm{C}\right)$. The OsOSC12 mutants were selected from a TILLING population as described below. Selected mutant plants were backcrossed to WT (Oryza sativa L. cv. Zhonghual1) 
a

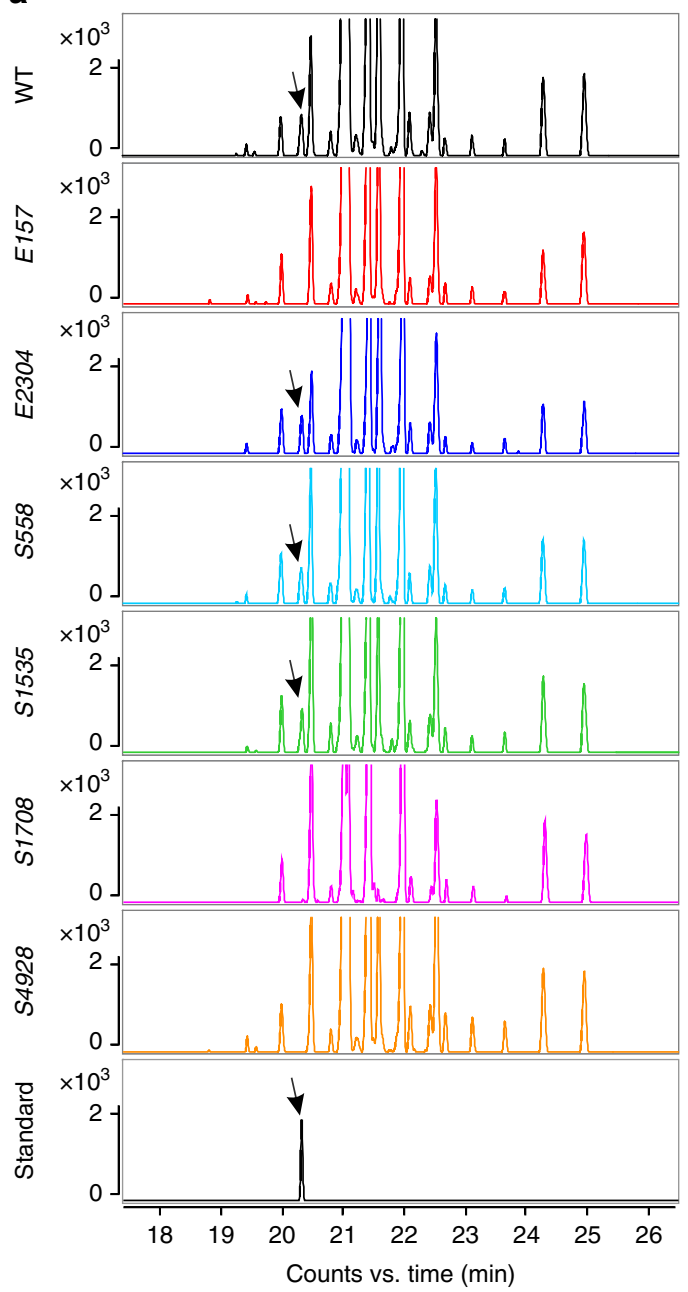

b

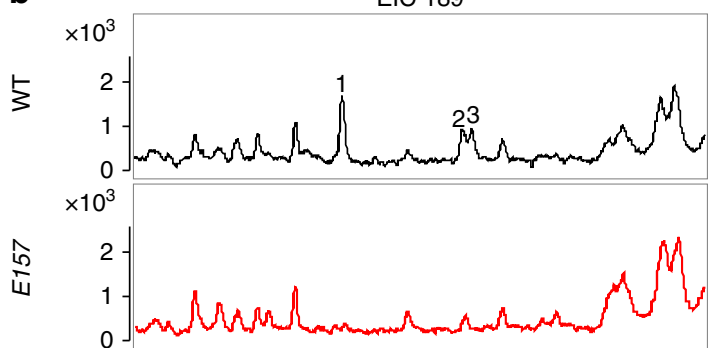

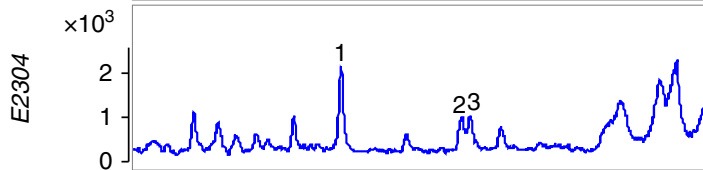
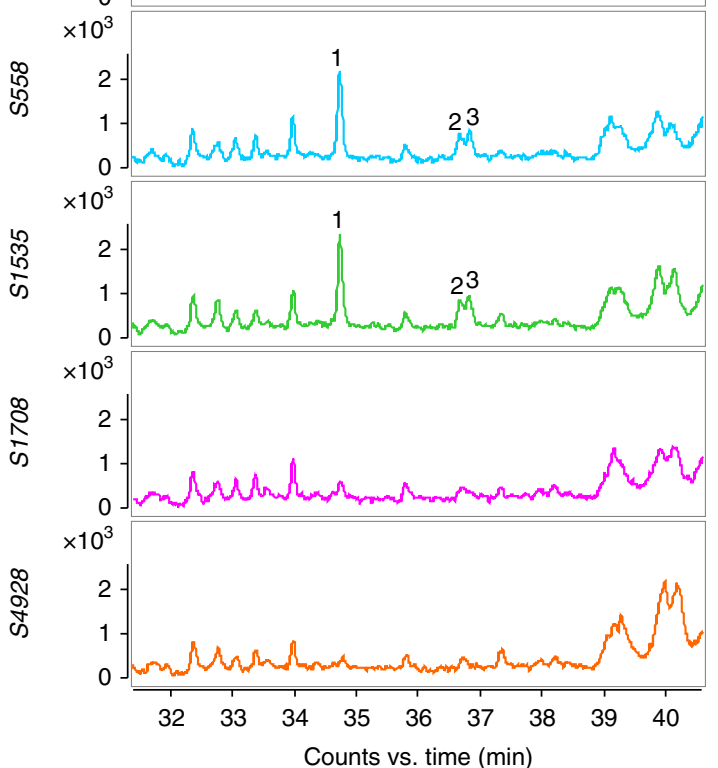

c<smiles>CC=C(C)CCCC(C)(C)C1CCCC=C1CC=C(C)CCC=C(C)CCC=C(C)C</smiles>

2,3-Oxidosqualene

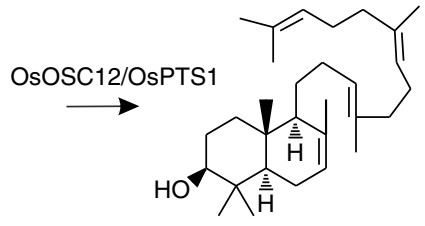

Poaceatapetol

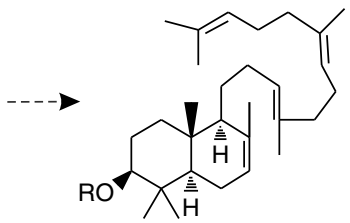

Poaceatapetol fatty acid ester

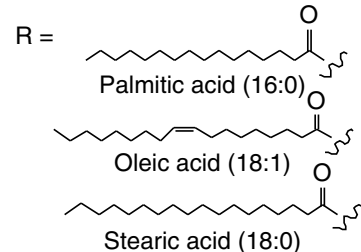

Stearic acid (18:0)

Fig. 5 The OsOSC12 committed triterpene ester pathway. a GC-MS profiles of the triterpene alcohol fraction of anther (S12) extracts from OsOSC12 mutant and WT plants. The arrow indicates the peaks present in the WT and the "silent" mutants, but absent in the loss-of-function mutants. Standard, purified poaceatapetol. EIC 189, extracted ion chromatograms at $m / z$ 189. The arrow indicates the poaceatapetol peak. b GC-MS profiles of the triterpene esters of anther (S12) extraction from OsOSC12 mutant and WT plants. 1: poaceatapetol palmitic acid (16:0) ester; 2: poaceatapetol oleic acid (18:1) ester; 3: poaceatapetol stearic acid (18:0) ester; EIC 189, extracted ion chromatograms at $\mathrm{m} / \mathrm{z} 189$. c The OsOSC12 committed triterpene pathway for biosynthesis of poaceatapetol esters

to remove background mutations. Selected mutant plants from E2304, S558, S1535, S1708, and S4928 were crossed to E157 for allelism test.

Northern blotting analysis. Rice tissues were snap-frozen in liquid nitrogen and ground with a mortar and pestle. Total RNA was extracted from the resulting powder using the TRIzol reagent (Invitrogen, Carlsbad, CA, USA). Gel analysis of the resulting RNA preparation was carried out using standard methods ${ }^{26}$. RNA probe labeling and hybridization were performed at two different stringency levels $\left(55^{\circ} \mathrm{C}\right.$ and $\left.68^{\circ} \mathrm{C}\right)$, with a washing protocol as described in the manual (version Jan 2006) provided with the DIG Northern Starter Kit (Roche Diagnostics, Mannheim, Germany).

Quantitative real-time PCR analysis. Anthers were excised at various developmental stages, as determined from the length of the anthers and checked using light microscopy. After snap-freezing the material, RNA isolation and cDNA synthesis was carried out using standard methods. Gene specific primers (OSCA8_1, _2, sequences given in Supplementary Table 3) were designed to amplify $862 \mathrm{bp}$ of the OsOSC12 sequence. An Actin gene (Os03g0718100, http://rapdb.dna.affrc.go.jp/) fragment (amplified using primers OsACT_1 and _2, see Supplementary Table 3) was used as the reference sequence. qRT-PCR was carried out using a SYBR Green ER qPCR SuperMix Universal Kit (Invitrogen, Carlsbad, CA, USA), applying an amplification regime of $94^{\circ} \mathrm{C}$ for $5 \mathrm{~min}$, followed by 40 cycles of $94^{\circ} \mathrm{C}$ for $30 \mathrm{~s}, 54^{\circ} \mathrm{C}$ for $30 \mathrm{~s}$, and $72^{\circ} \mathrm{C}$ for $45 \mathrm{~s}$. Experiments included three technical replicates and at least three biological replicates.

Rice transformation. The ubiquitin promoter was cloned into the binary vector pCAMBIA1301 by replacing the $\mathrm{p} 35 \mathrm{~S}$ promoter. The coding sequence of OsOSC12 (Os08g0223900, http://rapdb.dna.affrc.go.jp/) was inserted into the modified pCAMBIA1301 vector under the control of ubiquitin promoter to generate the transformation construct $U b i_{\text {pro }}:: O s O S C 12$. The resulting construct and the control 


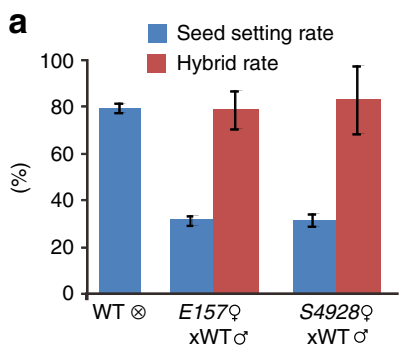

b

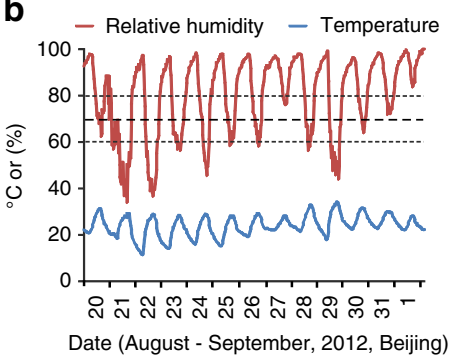

\section{d}

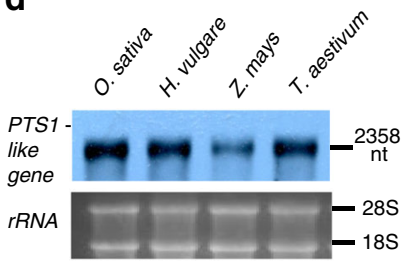

e

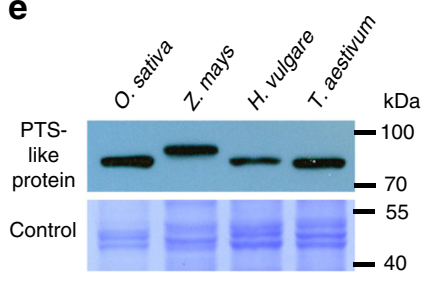

C

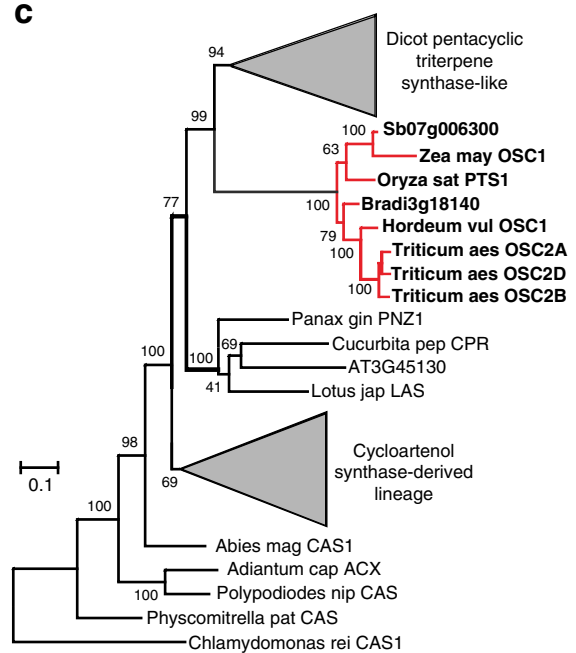

f

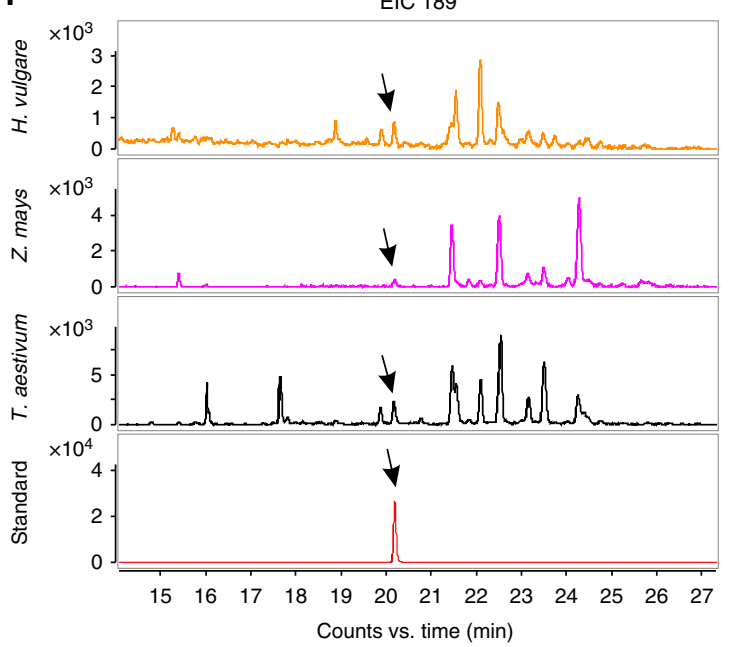

Fig. 6 HGMS-based hybrid seed production. a Seed setting rate and hybrid rate of the crosses of E157 and S4928 plants, with the WT plants. The data are presented as mean \pm s.d., $n=15$ panicles for seed setting rate, $n=300$ seeds for hybrid rate. $\mathbf{b}$ The variation in RH and temperature at the field site over the period of anthesis. Data were recorded at $1 \mathrm{~h}$ intervals by a detector suspended $10 \mathrm{~cm}$ above the canopy. $\mathbf{c}$ A simplified phylogeny of plant OSCs, based on their coding sequence. A maximum likelihood tree was constructed assuming the GTR $+\Gamma+$ I model. The gray triangles indicate groups of OSCs derived from the same lineage. Sequences shown in bold indicate poaceatapetol synthase-like genes. $\mathbf{d}$ Northern blotting analysis of transcription in the anthers of four major cereal species. e Western blotting demonstrates the presence of OsOSC12-like proteins in the anthers of other cereal species. $\mathbf{f}$ The GC/MS profile of the triterpene alcohol fraction of extracts of barley, maize and wheat anthers. Standard, purified poaceatapetol; EIC 189, extracted ion chromatograms at $m / z$ 189. The arrow indicates the poaceatapetol peak

vector pCAMBIA1301 were transformed into Agrobacterium tumefaciens strain EHA105 as a means of introducing it into rice calli induced from mature E157, S4928, S1708, and WT embryos. Transgenic calli were selected on a Murashige and Skoog ${ }^{27}$ medium containing $50 \mathrm{mg} \mathrm{L}^{-1}$ hygromycin B (Roche Diagnostics, Mannheim, Germany). Hygromycin resistant regenerants were transplanted into soil and grown either in a greenhouse or in the field.

Monoclonal antibody preparation and testing. A monoclonal anti-OsOSC12 antibody was generated by utilizing a bacterially expressed one of hydrophilic OsOSC12 protein fragment (aa 3-203) as an elicitor (Abmart, Shanghai, China). The specificity of the antibody was tested by immunoblotting of proteins extracted from roots, leaves, and flowers of WT and OsOSC12 over-expressing rice plants.

Protein extraction and western blotting analysis. To extract protein, $200 \mathrm{mg}$ of powdered frozen rice tissues were suspended in $500 \mu \mathrm{L}$ of Plant Protein Extraction Reagent (CWBIO, Beijing, China), followed by vortexing, incubating at $0{ }^{\circ} \mathrm{C}$ for 20 min, centrifuging $\left(7100 \times g, 20 \mathrm{~min}, 4^{\circ} \mathrm{C}\right)$, mixing the supernatant with an equal volume of $2 \times$ SDS loading buffer and boiling for $10 \mathrm{~min}$. A $5 \mu \mathrm{L}$ aliquot of each sample was loaded onto an $8 \%$ SDS-PAGE gel and electrophoresed at $100 \mathrm{~V}$ for 20 $\mathrm{min}$ then at $150 \mathrm{~V}$ for $50 \mathrm{~min}$. The gels were subsequently incubated in $25 \mathrm{mM}$ Tris, $192 \mathrm{mM}$ glycine, $20 \%$ methanol for $20 \mathrm{~min}$, while a PVDF membrane was wetted in methanol (5 min) and then equilibrated for $15 \mathrm{~min}$ in the same buffer. A wet transfer cell (Bio-Rad, Hercules, CA, USA) was used to transfer proteins from the gel to the membrane $\left(4^{\circ} \mathrm{C}, 80 \mathrm{~min}, 100 \mathrm{~V}\right)$. The membranes were blocked by exposure to $5 \% \mathrm{w} / \mathrm{v}$ powdered skimmed milk in Tris buffered saline with $0.05 \%(\mathrm{v} / \mathrm{v})$ Tween 20 (TBST pH 7.4, $10 \mathrm{mM}$ Tris, $100 \mathrm{mM} \mathrm{NaCl}$ ) overnight at $4^{\circ} \mathrm{C}$. A monoclonal rice anti-HSP (heat shock protein, accession Q69QQ6, $80 \mathrm{kDa}$, Cat. AbM51099-31-PU, BGI, Beijing, China) produced in mice was diluted in 1/10,000 and used as a control. The membranes carrying the transferred proteins were incubated with an anti-OsOSC12 antibody (1/500 dilution in TBST and 1\% w/v skimmed milk) for $1 \mathrm{~h}$ at room temperature, washed in TBST at room temperature
$(3 \times 10 \mathrm{~min})$, incubated with a goat anti mouse IgG-HRP conjugated secondary antibody (Cat. CW0102 CWBIO, Beijing, China) diluted 1/5000 in TBST and 1\% w/v skimmed milk, and well rinsed. Visualization of the conjugated secondary antibody was performed by supplying SuperSignal West Dura Extended Duration Substrate (Thermo Scientific, Shanghai Division, China) for $5 \mathrm{~min}$, followed by exposure to X-ray film.

In situ hybridization. WT anthers at various developmental stages were fixed in FAA (50\% v/v ethanol, $5 \% \mathrm{v} / \mathrm{v}$ acetic acid, $3.7 \% \mathrm{v} / \mathrm{v}$ formaldehyde) for $16 \mathrm{~h}$ at $4{ }^{\circ} \mathrm{C}$, and dehydrated by passing through an ethanol series

(50-60-75-80-95-100-100\%). The samples were then passed through a xylene-ethanol series, then embedded in Paraplast (Sigma-Aldrich, St. Louis, MO, USA) with six changes of Paraplast. The blocks were sectioned into $8 \mu \mathrm{m}$ slices using an RM 2235 (Leica, Wetzlar, Germany) rotary microtome and mounted onto Poly-Prep slides (Sigma-Aldrich, St. Louis, MO, USA). The sections were hybridized to either a sense or an antisense OsOSC12 probe. Probes were synthesized via PCR: a 273 bp OsOSC12 cDNA fragment (nucleotides 350-622, counted from the transcription start codon) was amplified from panicle-derived cDNA using primers incorporating the T7 polymerase binding site. For the antisense probe, the primer sequences were ANTISENSE_1,_2, while for the sense probe they were SENSE_1,_2 (Supplementary Table 3). Probes were labeled with digoxigenin (Cat. 11175041910, Roche Diagnostics, Mannheim, Germany) by transcribing the template using T7 polymerase (Roche Diagnostics, Mannheim, Germany), following the manufacturer's instructions. The sections were deparaffinized in xylene, rehydrated through a graded ethanol series and then air-dried. They were treated with $4 \mu \mathrm{g} \mathrm{mL}$ ${ }^{-1}$ proteinase $\mathrm{K}$ in $100 \mathrm{mM}$ Tris- $\mathrm{HCl}$, $\mathrm{pH} 8.0,50 \mathrm{mM}$ EDTA at $37^{\circ} \mathrm{C}$ for $30 \mathrm{~min}$ and then washed twice with distilled water for $5 \mathrm{~min}$ each. The sections are washed as following: twice with $1 \times \mathrm{PBS}\left(130 \mathrm{mM} \mathrm{NaCl}, 7 \mathrm{mM} \mathrm{Na} 2 \mathrm{HPO}_{4} \cdot 7 \mathrm{H}_{2} \mathrm{O}, 3 \mathrm{mM}\right.$ $\mathrm{NaH}_{2} \mathrm{PO}_{4} \cdot \mathrm{H}_{2} \mathrm{O}$ ) for $2 \mathrm{~min}, 0.2 \%$ glycine in $1 \times \mathrm{PBS}$ for 2 min, twice with $1 \times \mathrm{PBS}$ for $2 \mathrm{~min}$. The sections were subsequently treated with $40 \mathrm{~mL} 1 \times$ PBS with $0.5 \%$ acetic anhydride and $100 \mathrm{mM}$ triethanolamine for $5 \mathrm{~min}$ at room temperature, washed 
twice in $1 \times$ PBS for $5 \mathrm{~min}$. Sections were incubated at $50^{\circ} \mathrm{C}$ for $14-16 \mathrm{~h}$ with coverslips in hybridization buffer $(100-120 \mu \mathrm{l}$ per slide) containing the probes $\left(0.02 \mu \mathrm{g} \mathrm{mL}^{-1}\right)$. The hybridization buffer consisted of $50 \%$ deionized formamide, $0.3 \mathrm{M} \mathrm{NaCl}, 10 \%$ dextran sulfate, $10 \mathrm{mM}$ Tris-HCl, pH 7.5, 1 mM EDTA, $100 \mathrm{mM}$ DTT and $500 \mu \mathrm{g} \mathrm{mL}^{-1}$ Escherichia coli tRNA. After hybridization, successive washing steps were performed as follows: twice in $0.2 \times \mathrm{SSC}$, once in RNase A ( $5 \mu \mathrm{g}$ $\left.\mathrm{mL}^{-1}\right)$ in STE $(0.5 \mathrm{M} \mathrm{NaCl}, 10 \mathrm{mM}$ Tris- $\mathrm{HCl}, 5 \mathrm{mM}$ EDTA, $\mathrm{pH} 7.4)$ at $37^{\circ} \mathrm{C}$ for 30 min, twice in STE at $37^{\circ} \mathrm{C}$ for $5 \mathrm{~min}$ each, and twice in $0.2 \times \mathrm{SSC}$ at $55^{\circ} \mathrm{C}$ for 30 min each. Immunological detection of the hybridized probes was performed ccording to the manufacturer's manual with some modifications. The slides were soaked with $1 \times$ TBS $(150 \mathrm{mM} \mathrm{NaCl}, 100 \mathrm{mM}$ Tris- $\mathrm{HCl}, \mathrm{pH} 7.5)$ and then incubated with $1 \times$ blocking reagent (Roche) in TBS for $45 \mathrm{~min}$. They were further incubated with TBST (1\% BSA and $0.3 \%$ Triton X-100 in TBS) for $45 \mathrm{~min}$, followed by incubation with the diluted antidigoxigenin alkaline phosphatase conjugate (1:1250) in TBST for $2 \mathrm{~h}$. The slides were subsequently washed four times with TBST for $15 \mathrm{~min}$. The sections were rinsed with reaction buffer $(100 \mathrm{mM} \mathrm{NaCl}, 50$ $\mathrm{mM} \mathrm{MgCl} 2,100 \mathrm{mM}$ Tris- $\mathrm{HCl}, \mathrm{pH}$ 9.5), and then covered with reaction buffer contains $0.34 \mathrm{mg} \mathrm{mL}^{-1}$ nitroblue tetrazolium salt and $0.175 \mathrm{mg} \mathrm{mL}^{-1} 5$-bromo-4chloro-3-indolyl phosphate toluidinium salt. After incubation at room temperature for $12 \mathrm{~h}$ in the dark, the color reaction was stopped by immersing the slides in TE (10 mM Tris-HCl, $1 \mathrm{mM}$ EDTA), pH 7.5. The sections were observed under microscopy Olympus BX 51.

Immunolocalization of OsOSC12. For the purpose of immunolocalization, WT anthers at various developmental stages were fixed in $4 \% \mathrm{w} / \mathrm{v}$ paraformaldehyde in $0.1 \mathrm{M}$ PBS ( $\mathrm{pH} 7.0$ ) for $16 \mathrm{~h}$ at $4{ }^{\circ} \mathrm{C}$, dehydrated by passing through an ethanol series, and embedded in Paraplast. Microtome sections $(8 \mu \mathrm{m})$ were rehydrated in deionised water, and then treated with $3 \% \mathrm{v} / \mathrm{v}$ hydrogen peroxide for $10 \mathrm{~min}$ at room temperature. After rinsing three times in TBS, the sections were exposed to $10 \mathrm{mM}$ citrate buffer ( $\mathrm{pH} 6.0$ ) at $95^{\circ} \mathrm{C}$ for $10 \mathrm{~min}$, then rinsed three times in TBST and blocked by flooding with $5 \% \mathrm{w} / \mathrm{v}$ skimmed milk in TBST overnight at $4{ }^{\circ} \mathrm{C}$. The sections were incubated with an anti-OsOSC12 antibody (diluted 1/50 in 1\% $\mathrm{w} / \mathrm{v}$ skimmed milk) for $1 \mathrm{~h}$ at room temperature. Following three washes in TBST, the sections were incubated with goat anti-mouse IgG-HRP (Cat. CW0102 CWBIO, Beijing, China), diluted $1 / 200$ in $1 \% \mathrm{w} / \mathrm{v}$ skimmed milk, for $1 \mathrm{~h}$ at room temperature. Following three washes with TBST, the sections were treated with 3,3'-diaminobenzidine solution before observation by light microscopy.

\section{Selecting de novo OsOSC12 mutants using the TILLING method. Grains of cv.} Zhonghual1 were obtained from the Chinese Academy of Agricultural Science (Beijing, China). The mutagenesis treatment was carried out in $500 \mathrm{~mL}$ flasks, each of which contained $25 \mathrm{~g}$ grains; the period of exposure to $2 \mathrm{mM}$ sodium azide (SAZ) was $6 \mathrm{~h}$, while the exposure to $80 \mathrm{mM}$ ethyl methane sulfonate (EMS) was overnight $(18 \mathrm{~h})$. The $4950 \mathrm{M}_{1}$ fertile plants were allowed to self fertilize. DNA was extracted and pooled from the seedling per $\mathrm{M}_{2}$ plant. The DNA pools with each mixed by 8 individual DNA samples were subjected to the TILLING procedure directed at $\mathrm{OsOSC12}$; three pairs of gene-specific primers were utilized, one targeting exon 6 to 7 (primers Ex6-7_1,_2), the second exon 8 to 10 (Ex8-10_1,_2), and the third exon 16 to 18 (Ex16-18_1,_2) (Supplementary Table 3). Each $10 \mu \mathrm{L}$ reaction contained $5 \mathrm{ng}$ pooled DNA, $1 \times$ EX Taq buffer (Takara, Dalian, China), $0.2 \mathrm{mM}$ dNTP, $0.16 \mu \mathrm{M}$ of each primer, and $0.5 \mathrm{U}$ EX Taq polymerase (Takara, Dalian, China). The amplification program comprised an initial denaturation $\left(95^{\circ}\right.$ $\mathrm{C}$ for $2 \mathrm{~min}$ ); eight cycles of $94^{\circ} \mathrm{C}$ for $20 \mathrm{~s}, T_{\mathrm{m}}+3{ }^{\circ} \mathrm{C}$ to $T_{\mathrm{m}}-4^{\circ} \mathrm{C}$ decrementing $1^{\circ}$ $\mathrm{C}$ per cycle for $30 \mathrm{~s}, 72^{\circ} \mathrm{C}$ for $1 \mathrm{~min}$; then 35 cycles of $94^{\circ} \mathrm{C}$ for $20 \mathrm{~s}, T_{\mathrm{m}}-5^{\circ} \mathrm{C}$ for $30 \mathrm{~s}, 72^{\circ} \mathrm{C}$ for $1 \mathrm{~min} ; 72^{\circ} \mathrm{C}$ for $5 \mathrm{~min}$. Post amplification, duplex formation was carried out by imposing an initial denaturation $\left(95^{\circ} \mathrm{C} / 10 \mathrm{~min}\right)$, followed by a $0.3^{\circ} \mathrm{C}$ stepwise reduction in temperature from $70^{\circ} \mathrm{C}$ to $49^{\circ} \mathrm{C}$ with $20 \mathrm{~s}$ spent at each temperature. Heteroduplexes were cleaved using a crude celery juice extract and processed following ${ }^{28}$. The products were size-fractionated by denaturing polyacrylamide gel electrophoresis using a Li-Cor 4300 DNA analyzer (LI-COR, Lincoln, NE, USA). TILLING gels were scanned using GelBuddy and Ecotilling gel analysis software ${ }^{29}$. Putative mutations were validated by sequencing on an ABI 3730XL sequencer (Applied Biosystems, Foster City, CA, USA).

Assay of pollen germination and dehydration. Pistils were excised and placed upright on agar (1.5\%), then dusted with pollen from a freshly dehiscing anther. The behavior of the pollen was tracked by light microscopy. A humidifier was used to generate high $\mathrm{RH}$ conditions. To measure the rate of pollen dehydration, pollen from a freshly dehiscing anther was released onto a dry glass slide and monitored by light microscopy. To examine pollen tube growth, the pistils of the pollinated flowers were fixed in ethanol:acetic acid (3:1) solution for $5 \mathrm{~min}$, transferred into 1 $\mathrm{N} \mathrm{NaOH}$, incubated at $60{ }^{\circ} \mathrm{C}$ for $30 \mathrm{~min}$ and stained with aniline blue $(0.1 \%$ in 0.1 $\mathrm{M} \mathrm{K}_{3} \mathrm{PO}_{4}$ ).

Extraction and analysis of pollen coat. For small-scale analysis, pollen coats were extracted by soaking $200 \mathrm{mg}$ pollen in $2 \mathrm{~mL}$ of either ethyl ether or chloroform for $1 \mathrm{~min}, 5 \mathrm{~min}, 20 \mathrm{~min}, 60 \mathrm{~min}$ and $12 \mathrm{~h}$. These extracts were analyzed using an Agilent 7890/5977A GC-MS device (Agilent Technologies, Santa Rosa, CA, USA) equipped with DB-5HT column $(30 \mathrm{~m} \times 250 \mu \mathrm{m}$ internal diameter, $0.1 \mu \mathrm{m}$ film $)$ using electron ionization (EI). The inlet, transfer line, and ion source temperatures were set to, respectively, $340^{\circ} \mathrm{C}, 280^{\circ} \mathrm{C}$, and $250{ }^{\circ} \mathrm{C}$ and the oven profile comprised a $2 \mathrm{~min}$ period at $60^{\circ} \mathrm{C}$ and $1 \mathrm{~min}$ at $220^{\circ} \mathrm{C}$, with the temperature increased at $40^{\circ} \mathrm{C}$ $\min ^{-1}$, followed by $8 \mathrm{~min}$ at $340^{\circ} \mathrm{C}$, with the temperature raised at $4^{\circ} \mathrm{C} \mathrm{min}^{-1}$. The flow rate of helium gas was $2.6 \mathrm{~mL} \mathrm{~min}^{-1}$. Splitless injections $(1 \mu \mathrm{L})$ were used and mass spectral data between $m / z 50$ and 800 were acquired. For fatty acid analysis, the PCE were esterified by bis- $N, N$-(trimethylsilyl) trifluoroacetamide (SigmaAldrich) in pyridine for $30 \mathrm{~min}$ at $60^{\circ} \mathrm{C}$ and quantified using standards as following: palmitic acid, stearic acid, and linolenic acid (Sigma-Aldrich, Shanghai, China). For the large-scale extraction of triterpene esters, $200 \mathrm{~g}$ of pollen grains were extracted with $2 \times 250 \mathrm{~mL}$ ethyl ether and the extracts were combined and dried. The crude extracted product was suspended in hexane and separated by using $20 \mathrm{~g}$ silica gel column chromatography with a gradient eluents system including dichloromethane in hexane: $10 \%$ for $2 \mathrm{CV}$ (column volume), $20 \%$ for 10 $\mathrm{CV}$, and $100 \%$ for $2 \mathrm{CV}$. Each fraction collected in $20 \mathrm{~mL}$ test tube was monitored by TLC analysis. To prepare WT and E157 PCE extracts for the exogenous supply experiment, $5 \mathrm{~g}$ of WT or mutant pollen were extracted as above, yielding $200 \mathrm{mg}$ WT PCE and $100 \mathrm{mg}$ E157 PCE.

Exogenous application experiment. The WT and E157 pollen from a freshly dehiscing anther were soaked for $20 \mathrm{~min}$ in different treatments (Supplementary Table 4). The treated pollen grains were then placed onto a dry glass slide and monitored by light microscopy. The dehydration time was recorded when over than $90 \%$ of pollen was dried, for up to $1 \mathrm{~h}$. Experiments included three technical replicates and at least three biological replicates.

Triterpene purification and structural identification. Metabolites were extracted from $100 \mathrm{mg}$ of lyophilized S12 anther tissue. In brief, homogenized samples was saponified in $10 \% \mathrm{KOH}(\mathrm{w} / \mathrm{v})$ in $80 \% \mathrm{EtOH}(\mathrm{v} / \mathrm{v})$ at $70{ }^{\circ} \mathrm{C}$ for $1 \mathrm{~h}$ and extracted three times with an equal volume of hexane. Crude extracts were derivatized by treatment with $100 \mu \mathrm{L} \mathrm{N}$-methyl- $N$-trimethylsilyl-trifluoroacetamide (MSTFA) at $60{ }^{\circ} \mathrm{C}$ for $30 \mathrm{~min}$, then analyzed using same GC-MS equipment. The inlet was changed to $280^{\circ} \mathrm{C}$ and the oven profile comprised a $2 \mathrm{~min}$ period at $170{ }^{\circ} \mathrm{C}$ and 4 min at $290^{\circ} \mathrm{C}$, with the temperature increased at $6^{\circ} \mathrm{C} \mathrm{min}-1$, followed increasing to $340^{\circ} \mathrm{C}$, with the temperature raised at $10^{\circ} \mathrm{C} \mathrm{min}^{-1}$. The flow rate of helium gas was $0.8 \mathrm{~mL} \mathrm{~min}^{-1}$. Splitless injections $(1 \mu \mathrm{L})$ were used and mass spectral data between $\mathrm{m} / z 50$ and 650 were acquired. For the large-scale extraction of triterpenes, about 6 $\mathrm{kg}$ of rice panicles at the anther development stages S9-S11 were saponified by using the solvent of $10 \% \mathrm{w} / \mathrm{v}$ potassium hydroxide and $80 \% \mathrm{v} / \mathrm{v}$ ethanol. The $\mathrm{n}$ hexane extraction $(52.23 \mathrm{~g}$ ) was dried and separated by column chromatography using silica gel as adsorbent and 6:1 hexane:ethyl acetate as eluent. The triterpene fractions $(9.1 \mathrm{mg})$ were dried and dissolved in methanol and further purified by reverse-phase HPLC on an Agilent 1200 series LC equipped with a semipreparative column (Eclipse XDB-C18, $5 \mu \mathrm{m}, 9.4 \times 250 \mathrm{~mm}$ ) using the following profile: $90-100 \%$ methanol for $20 \mathrm{~min}, 100 \%$ methanol for $45 \mathrm{~min}$ at $2.5 \mathrm{~mL} \mathrm{~min}^{-1}$ flow rate. The semi-preparative fractions were monitored by GC-MS. We found a purified compound (poaceatapetol) at retention time $20.3 \mathrm{~min}$ and ca. $1 \mathrm{mg}$ compound was obtained from this fraction. To estimate molecular mass, the purified compound was directly injected into an Agilent 6540 Quadrupole time-offlight mass spectrometer and positive ESI was applied. The ESI capillary voltage was set to $3.5 \mathrm{kV}$, the nitrogen gas temperature was set to $320^{\circ} \mathrm{C}$, the drying gas flow rate to $12 \mathrm{~L} \mathrm{~min}^{-1}$, the nebulizer gas pressure to $25 \mathrm{psi}$, the fragment or voltage to $120 \mathrm{~V}$, the skimmer voltage to $65 \mathrm{~V}$ and the capillary voltage to $4 \mathrm{kV}$. A reference mass correction solution 121.0509 and 922.0098 (Agilent Technologies, Santa Clara, CA) was infused during the analysis to improve accuracy. Mass data (from $m / z 50$ to 1000) were collected and interpreted using Agilent MassHunter B.06 software. The purified compound was analyzed in an $800 \mathrm{MHz}$ NMR device (Bruker Biospin, Karlsruhe, Germany). ${ }^{1} \mathrm{H}$ - and ${ }^{13} \mathrm{C}-\mathrm{NMR}(800 \mathrm{MHz})$ and $2 \mathrm{D}$ NMR (heteronuclear single quantum coherence (HSQC), heteronuclear multiplebond correlation (HMBC), rotating frame overhauser effect spectroscopy (ROESY), and homonuclear chemical shift (COSY)) were measured, using $\mathrm{C}_{6} \mathrm{D}_{6}$ as an NMR solvent and internal standard.

The HR-ESI-MS displayed a pseudo molecular ion $[\mathrm{M}+\mathrm{H}]^{+}$at $\mathrm{m} / z 427.3929$, consistent with the molecular formula of $\mathrm{C}_{30} \mathrm{H}_{50} \mathrm{O}$ (calcd for $\mathrm{C}_{30} \mathrm{H}_{51} \mathrm{O}, 427.3940$ ). The ${ }^{1} \mathrm{H}-\mathrm{NMR}$ spectrum $\left(800 \mathrm{MHz}, \mathrm{C}_{6} \mathrm{D}_{6}\right)$ showed the presence of five vinylic methyls (each $3 \mathrm{H}, \mathrm{s})$ at $\delta_{\mathrm{H}}(\mathrm{ppm}) 1.77,1.65,1.63,1.58$, and 1.69. Four olefinic protons were observed at $\delta_{\mathrm{H}}(\mathrm{ppm}) 5.42(\mathrm{br} \mathrm{s}), 5.31(\mathrm{br} \mathrm{t}), 5.33(\mathrm{br} \mathrm{t})$, and $5.25(\mathrm{br} \mathrm{t})$, which, together with the eight olefinic carbons displayed in the ${ }^{13} \mathrm{C} \mathrm{NMR}$, indicated that four double bonds were present in this compound. This above findings suggested that the purified compound had a bicyclic framework. Inspection of the ${ }^{1} \mathrm{H}-{ }^{1} \mathrm{H}$ COSY spectrum led to the establishment of spin-spin coupling systems as depicted in bold line in Supplementary Fig. 11c. In the HMBC spectrum, the cross peaks of Me-23 $(\mathrm{Me}-24) / \mathrm{C}-3\left(\delta_{\mathrm{C}} 78.7\right), \mathrm{C}-4$, and C-5; Me-25 $\left(\delta_{\mathrm{H}} 0.76, \mathrm{~s}\right) / \mathrm{C}-1\left(\delta_{\mathrm{C}}\right.$ $37.5), \mathrm{C}-5, \mathrm{C}-9\left(\delta_{\mathrm{C}} 54.4\right)$, and C-10; and Me-26 $\left(\delta_{\mathrm{H}} 1.77, \mathrm{~s}\right) / \mathrm{C}-7\left(\delta_{\mathrm{C}} 122.5\right), \mathrm{C}-8\left(\delta_{\mathrm{C}}\right.$ $135.2)$, and $\mathrm{C}-9$ indicated that the purified compound had a bicyclic scaffold with a methyl and a side chain attached to C-8 and C-9, respectively, and a hydroxy group at C-3. HMBC correlations of Me-27/C-13, C-14, and C-15; Me-28/C-17, C-18, and $\mathrm{C}-19$; and $\mathrm{Me}-29(\mathrm{Me}-30) / \mathrm{C}-21$ and $\mathrm{C}-22$ furnished the structure of the side chain. The gross structure of this compound was thus established. The stereochemistry of this compound was determined by the ROESY spectrum in 
combination with analysis of coupling constant values of ${ }^{1} \mathrm{H}$ NMR and chemical shift values of ${ }^{13} \mathrm{C}$ NMR. It should be noted that $\mathrm{H}-3$ resonated as a doublet of doublet with $J$ values at 11.2 and $2.7 \mathrm{~Hz}$ in this compound. The large $J$ value of 11.2 $\mathrm{Hz}$ indicated that $\mathrm{H}-3$ was axially $\alpha$-oriented, and accordingly the hydroxyl group at $\mathrm{C}-3$ was $\beta$-oriented. The NOE correlations (Supplementary Fig. 11c) of $\mathrm{H}-3 / \mathrm{H}_{3}-$ 23 and $\mathrm{H}-3 / \mathrm{H}-5$ also supported the above conclusion. The NOE correlations of $\mathrm{H}-$ $13 / \mathrm{H}_{2}-15$ and $\mathrm{H}-17 / \mathrm{H}_{2}-19$ indicated that both of the $\Delta^{13}$ and $\Delta^{17}$ double bonds were $E$-configured. The relatively upfield shifted resonances for C-27 $\left(\delta_{\mathrm{C}} 16.3\right)$ and C-28 $\left(\delta_{\mathrm{C}} 16.1\right)$ in ${ }^{13} \mathrm{C}$ NMR also suggested that they were syn to C-12 and C-16, respectively, because of the $\gamma$-gauche effect ${ }^{30}$, which also supported that both of the $\Delta^{13}$ and $\Delta^{17}$ double bonds were $E$-configured. Therefore, this purified compound was identified as polypoda-7,13E,17E,21-tetraene-3 $\beta$-ol. A literature search revealed that the purified compound was the same as a bicyclic triterpene that has been isolated from bark of Vietnamese Cratoxylum cochinchinense ${ }^{31}$ and yeast expression of a mutant of $\beta$-amyrin synthase from Euphorbia tirucalli ${ }^{32}$ previously. The NMR data were assigned with the aid of 2D NMR (Supplementary Fig. 11b), which was consistent with those reported ${ }^{31,32}$.

Physicochemical properties analysis. For IR spectroscopy, the sample was first dissolved in methanol at $0.05 \mathrm{~g} \mathrm{~mL}^{-1}$. A drop of this solution is deposited on surface of $\mathrm{KBr}$ cell. The solution was then evaporated to dryness and the film formed on the cell is analyzed directly on a Nicolet IN 10 Micro FTIR spectrometer by transmission mode (Supplementary Data 2). For UV spectroscopy, the same solution was analyzed by the DAD detector of an Agilent 1200 series LC and scanned from 210 to $600 \mathrm{~nm}$ (Supplementary Data 2). For optical rotation, the same solution was analyzed on a Anton Paar MCP100 polarimeter and the specific rotation was $[\alpha]^{25}{ }_{\mathrm{D}}=+7.25\left(c=0.035, \mathrm{CHCl}_{3}\right)$. Values represent means \pm s.d. of three technical replicates.

Heterologous expression in Pichia pastoris. Total RNA isolated from rice anther was converted into cDNA using SuperScript II reverse transcriptase (Invitrogen, Carlsbad, CA, USA) following the manufacturer's protocol. The resulting cDNA was used as a template to isolate OsOSC12 by PCR, using the primer pair OSC8S/ OSC8A (Supplementary Table 3) and Phusion DNA polymerase (New England Biolabs, NEB). The PCR program comprised an initial denaturation $\left(98^{\circ} \mathrm{C} / 30 \mathrm{~s}\right)$, followed by 35 cycles of $98^{\circ} \mathrm{C}$ for $10 \mathrm{~s}, 60^{\circ} \mathrm{C}$ for $30 \mathrm{~s}, 72^{\circ} \mathrm{C}$ for $45 \mathrm{~s}$, with a final extension step of $72^{\circ} \mathrm{C}$ for $7 \mathrm{~min}$. The amplicon was separated by agarose gel electrophoresis and gel-purified using a Gel Extraction Kit (Qiagen, Valencia, CA, USA). The $2.3 \mathrm{~kb}$ product was inserted into the pGEM-T-Easy vector (Promega, Madison, WI, USA) for sequencing. SnOsOSC12 (Supplementary Data 3) was made by synthesis, with yeast-preferred codons incorporated into the sequence ${ }^{33}$, then introduced into the pUC57 vector (Shanghai Sangon Biological, Shanghai, China). All mutants were generated by PCR (primers Exxx or Sxxx_Mu_1,_2 in Supplementary Table 3) based site-directed mutagenesis as the manual of QuickChange site-directed mutagenesis kit (Stratagene Inc., La Jolla, CA). The plasmids were double-digested with Sac II and Spe I and ligated into the yeast expression vector pPICZa A (Invitrogen, Carlsbad, CA, USA) driven by a methanol-inducible promoter. The plasmids were introduced into $P$. pastoris WT strain X33 using electroporation. X33s harboring $\mathrm{SnOsOSC12}$ and its mutagenized genes were grown at $30{ }^{\circ} \mathrm{C}$ in minimal glycerol medium (MGY, $1.34 \%$ yeast nitrogen base, $1 \%$ glycerol, $4 \times 10^{-5} \%$ biotin) to $\mathrm{OD}_{600}=2-6$. The cells were collected by centrifugation, resuspended in minimal methanol medium (MM, $1.34 \%$ yeast nitrogen base, $4 \times 10^{-5} \%$ biotin, $0.5 \%$ methanol) to $\mathrm{OD}_{600}=1.0$ and incubated at $30^{\circ} \mathrm{C}$ for $24 \mathrm{~h}$. Cells were collected from $25 \mathrm{~mL}$ culture disrupted with $2 \mathrm{~mL} 10 \% \mathrm{KOH}(\mathrm{w} / \mathrm{v})$ in $80 \% \mathrm{EtOH}$ $(\mathrm{v} / \mathrm{v})$. The refluxed products were extracted twice with $2 \mathrm{~mL}$ hexane, and combined both hexane solutions to obtain the crude extract. The extracts were either directly derivatized using MSTFA and analyzed by GC-MS as described above.

Scanning electron microscopy. S12 anthers and stigmas sampled simultaneously were fixed in FAA for $24 \mathrm{~h}$ at $4{ }^{\circ} \mathrm{C}$, dehydrated by passing through an ethanol series, then through an ethanol-isoamyl acetate series, and finally dried at liquid $\mathrm{CO}_{2}$ critical point for $4 \mathrm{~h}$. Individual anthers and stigmas were mounted on SEM stubs, coated with gold and scanned using a Hitachi S-4800 device (Hitachi, Tokyo, Japan), with the acceleration voltage set to $10 \mathrm{kV}$. To avoid interference from organic solvents, the S12 anthers were also dehydrated at room temperature, then directly coated with gold.

Transmission electron microscopy. WT and mutant pollen grains at stage 14 were fixed in $4 \%$ paraformaldehyde and $3 \% \mathrm{v} / \mathrm{v}$ glutaraldehyde in $0.1 \mathrm{M} \mathrm{PBS}(\mathrm{pH}$ 7.0 ), then post fixed in $1 \% \mathrm{w} / \mathrm{v} \mathrm{OsO} \mathrm{O}_{4}$ in $\mathrm{PBS}$. The samples were dehydrated by passing through an ethanol series, then embedded in Spurr's resin (Sigma-Aldrich, St. Louis, MO, USA) which was subsequently polymerized at $60^{\circ} \mathrm{C}$ for $24 \mathrm{~h}$. Ultrathin sections $(70 \mathrm{~nm}$ ) were made using a diamond knife microtome (Leica Ultracut R). The sections were placed on 100 mesh copper grids and sequentially stained first in $2 \% \mathrm{w} / \mathrm{v}$ uranyl acetate for $30 \mathrm{~min}$ and then in $0.2 \% \mathrm{w} / \mathrm{v}$ aqueous lead citrate for $5 \mathrm{~min}$. Sections were examined using a JEM-1230 device (JEOL, Japan) operating at $80 \mathrm{kV}$. For cryosectioning, S14 pollen was suspended in 20\% w/v BSA in $0.1 \mathrm{M}$ PBS, then transferred into $0.05 \mathrm{~mm}$ deep wells, in which they were frozen in a high pressure freezing machine HPF Compact 01 (M. Wohlwend $\mathrm{GmbH}$,
Switzerland). The specimens were then placed in freeze-substitution solution (1\% $\mathrm{w} / \mathrm{v} \mathrm{OsO}_{4}, 0.1 \% \mathrm{w} / \mathrm{v}$ uranyl acetate in acetone) and transferred into a Leica AFS2 freeze-substitution machine. The freeze-substitution procedure began with holding the samples at $-90^{\circ} \mathrm{C}$ for $30 \mathrm{~h}$, followed by $-60^{\circ} \mathrm{C}$ for $24 \mathrm{~h},-30^{\circ} \mathrm{C}$ for $18 \mathrm{~h}$ and $-20^{\circ} \mathrm{C}$ for $2 \mathrm{~h}$. During the temperature transitions, the temperature was increased gradually (over $8 \mathrm{~h}$ for the first transition, $4 \mathrm{~h}$ for the second and $1 \mathrm{~h}$ for the third). After warming to $0{ }^{\circ} \mathrm{C}$, the specimens were washed three times in acetone and then warmed to room temperature, before infiltrating with SPI-PON 812 resin. The resin was allowed to polymerize at $45^{\circ} \mathrm{C}$ for $18 \mathrm{~h}$, followed by $24 \mathrm{~h}$ at $60^{\circ} \mathrm{C}$. Ultrathin sections were cut and observed as described above.

Sequence alignment and phylogenetic analysis. A multiple alignment of OSC polypeptide sequences was performed, and a codon matrix produced using the Muscle alignment package provided in MEGA v5.1 software ${ }^{34}$. The same package was also used to conduct a phylogenetic analysis, based on codon alignments and the maximum likelihood method, assuming the GTR $+\Gamma+I$ substitution model.

Data availability. The authors declare that all data supporting the findings of this study are provided in the manuscript and its supplementary files or are available from the corresponding author upon request.

Received: 21 December 2016 Accepted: 16 January 2018 Published online: 09 February 2018

\section{References}

1. Tester, M. \& Langridge, P. Breeding technologies to increase crop production in a changing world. Science 327, 818-822 (2010).

2. Shi, M. The discovery and preliminary studies of the photoperiod-sensitive recessive male sterile rice (Oryza sativa L. subsp. japonica). Sci. Agric. Sin. 2, 44-48 (1985).

3. Luo, X., Qiu, Z. \& Li, R. Pei'ai 64S, a dual purpose sterile line whose sterility is induced by low critical temperature. Hybrid Rice 1, 27-29 (1992).

4. Fan, Y. et al. PMS1T, producing phased small-interfering RNAs, regulates photoperiod-sensitive male sterility in rice. Proc. Natl Acad. Sci. USA 113, 15144-15149 (2016).

5. Ding, J. et al. A long noncoding RNA regulates photoperiod-sensitive male sterility, an essential component of hybrid rice. Proc. Natl Acad. Sci. USA 109, 2654-2659 (2012)

6. Zhou, H. et al. Photoperiod- and thermo-sensitive genic male sterility in rice are caused by a point mutation in a novel noncoding RNA that produces a small RNA. Cell Res. 22, 649-660 (2012).

7. Huang, X. et al. Genomic analysis of hybrid rice varieties reveals numerous superior alleles that contribute to heterosis. Nat. Commun. 6, 6258 (2015).

8. Si, H., Liu, W., Fu, Y., Sun, Z. \& Hu, G. Current situation and suggestions for development of two-line hybrid rice in China. Chin. J. Rice Sci. 25, 544-552 (2011).

9. Pacinia, E. \& Hesseb, M. Pollenkitt - its composition, forms and functions. Flora 200, 399-415 (2005).

10. Taylor, L. P. \& Hepler, P. K. Pollen germination and tube growth. Annu. Rev. Plant Physiol. Plant Mol. Biol. 48, 461-491 (1997).

11. Piffanelli, P., Ross, J. H. E. \& Murphy, D. J. Biogenesis and function of the lipidic structures of pollen grains. Sex. Plant Reprod. 11, 65-80 (1998).

12. Dobson, H. E. M. \& Bergstrom, G. The ecology and evolution of pollen odors. Plant Syst. Evol. 222, 63-87 (2000).

13. Hernandez-Pinzon, I., Ross, J. H., Barnes, K. A., Damant, A. P. \& Murphy, D. J. Composition and role of tapetal lipid bodies in the biogenesis of the pollen coat of Brassica napus. Planta 208, 588-598 (1999).

14. Ariizumi, T. \& Toriyama, K. Genetic regulation of sporopollenin synthesis and pollen exine development. Annu. Rev. Plant Biol. 62, 437-460 (2011).

15. Zhang, D., Luo, X. \& Zhu, L. Cytological analysis and genetic control of rice anther development. J. Genet. Genom. 38, 379-390 (2011).

16. Gong, F., Wu, X. \& Wang, W. Diversity and function of maize pollen coat proteins: from biochemistry to proteomics. Front. Plant Sci. 6, 199 (2015).

17. Shi, J., Cui, M., Yang, L., Kim, Y. \& Zhang, D. Genetic and biochemical mechanisms of pollen wall development. Trends Plant Sci. 20, 741-753 (2015).

18. Preuss, D., Lemieux, B., Yen, G. \& Davis, R. W. A conditional sterile mutation eliminates surface components from Arabidopsis pollen and disrupts cell signaling during fertilization. Genes Dev. 7, 974-985 (1993).

19. Osbourn, A., Goss, R. J. M. \& Field, R. A. The saponins: polar isoprenoids with important and diverse biological activities. Nat. Prod. Rep. 28, 1261-1268 (2011).

20. Thimmappa, R., Geisler, K., Louveau, T., O'Maille, P. \& Osbourn, A. Triterpene biosynthesis in plants. Annu. Rev. Plant Biol. 65, 225-257 (2014). 
21. Inagaki, Y.-S. et al. Investigation of the potential for triterpene synthesis in rice through genome mining and metabolic engineering. New Phytol. 191, 432-448 (2011).

22. Xue, Z. et al. Divergent evolution of oxidosqualene cyclases in plants. New Phytol. 193, 1022-1038 (2012).

23. Wolters-Arts, M., Lush, W. M. \& Mariani, C. Lipids are required for directional pollen-tube growth. Nature 392, 818-820 (1998).

24. Yuan, L. Hybrid rice technology for food security in the world. Crop Res. 18, 185-186 (2004).

25. Zhang, H. et al. Carbon starved anther encodes a MYB domain protein that regulates sugar partitioning required for rice pollen development. Plant Cell 22, 672-689 (2010).

26. Sambrook, J. \& Russel, D. W. Molecular Cloning: A Laboratory Manual. 3rd edn, (Cold Spring Harbor Laboratory Press, New York, 2000).

27. Murashige, T. \& Skoog, F. A revised medium for rapid growth and bio-assays with tobacco tissue cultures. Physiol. Plant. 15, 473-497 (1962).

28. Till, B. J. et al. High-throughput TILLING for functional genomics. Methods Mol. Biol. 236, 205-220 (2003).

29. Zerr, T. \& Henikoff, S. Automated band mapping in electrophoreticgel images using background information. Nucleic Acids Res. 33, 2806-2812 (2005).

30. Kleinpeter, E. \& Seidl, P. R. The $\gamma$ - and the $\delta$-effects in ${ }^{13} \mathrm{C}$ NMR spectroscopy in terms of nuclear chemical shielding (NCS) analysis. J. Phys. Org. Chem. 17, 680-685 (2004).

31. Nguyen, L. H. D. \& Harrison, L. J. Triterpenoid and xanthone constituents of Cratoxylum cochinchinense. Phytochemistry 50, 471-476 (1998).

32. Ito, R. et al. $\beta$-amyrin synthase from Euphorbia tirucalli. steric bulk, not the $\pi$ electrons of phe, at position 474 has a key role in affording the correct folding of the substrate to complete the normal polycyclization cascade. Org. Biomol. Chem. 12, 3836-3846 (2014).

33. Sun, J., Xu, X., Xue, Z., Snyder, J. H. \& Qi, X. Functional analysis of a rice oxidosqualene cyclase through total gene synthesis. Mol. Plant 6, 1726-1729 (2013).

34. Tamura, K. et al. MEGA5: molecular evolutionary genetics analysis using maximum likelihood, evolutionary distance, and maximum parsimony methods. Mol. Biol. Evol. 28, 2731-2739 (2011).

\section{Acknowledgements}

This work was supported by funds from the National Natural Science Foundation (grant no. 31530050, 31370337 and 31170278), National Transgenic Megaproject of China (grant no. 2016ZX08009) and the Ministry of Science and Technology (grant no. 2013CB127000) of China. We thank C.M. Liu at the Institute of Botany of the Chinese Academy of Sciences (IBCAS) for providing the rice EMS population. We thank F.Q.

Dong and Y.H. Xiao at IBCAS for technical assistance with TEM and SEM analyses. We thank W.Z. He at the National Institute of Biological Sciences, Beijing (NIBS) for technical assistance of analysis of cyro-ultramicrotome sections. We thank Y.N. Wang at Capital Medical University and N. Xu at Tsinghua University for NMR analysis. We thank Z. Xue, B. Han (IBCAS) and L.D. Han (Chinese academy of agricultural sciences) for assistance in metabolite analysis. We thank A. Osbourn, R. Thimmappa, H.W. Nutzmann and A. Orme at John Innes Centre, H. Ma at Fudan University and R. Peters at Iowa State University for the critical comments.

\section{Author contributions}

Z.X. and X.Q. designed all experiments. Z.X., X.X., Y. Zhou., Y. Zhang., D.L. and B.Z performed the experiments. Z.X., X.X., X.W., L.D. and X.Q. contributed to data analysis and manuscript preparation. Z.X., X.W. and X.Q. wrote the manuscript.

\section{Additional information}

Supplementary Information accompanies this paper at https://doi.org/10.1038/s41467018-03048-8.

Competing interests: The authors declare no competing financial interests.

Reprints and permission information is available online at http://npg.nature.com/ reprintsandpermissions/

Publisher's note: Springer Nature remains neutral with regard to jurisdictional claims in published maps and institutional affiliations.

(c) (i) Open Access This article is licensed under a Creative Commons cc Attribution 4.0 International License, which permits use, sharing, adaptation, distribution and reproduction in any medium or format, as long as you give appropriate credit to the original author(s) and the source, provide a link to the Creative Commons license, and indicate if changes were made. The images or other third party material in this article are included in the article's Creative Commons license, unless indicated otherwise in a credit line to the material. If material is not included in the article's Creative Commons license and your intended use is not permitted by statutory regulation or exceeds the permitted use, you will need to obtain permission directly from the copyright holder. To view a copy of this license, visit http://creativecommons.org/ licenses/by/4.0/.

(C) The Author(s) 2018 